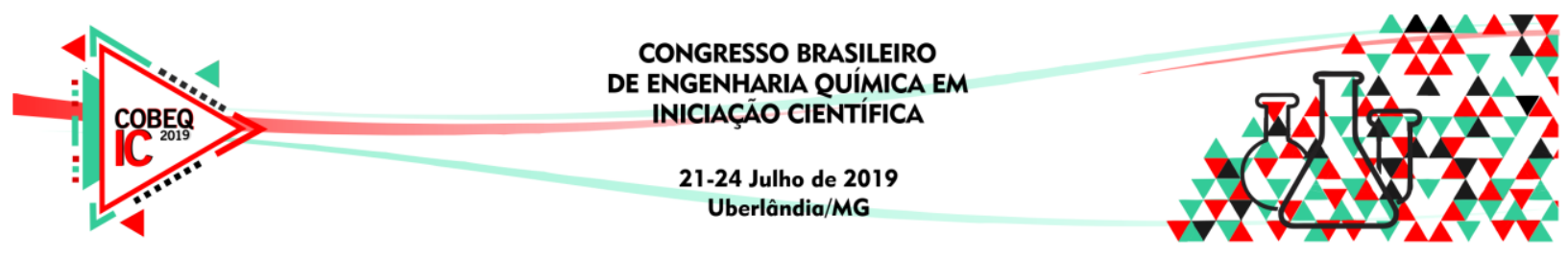

\title{
ANÁLISE DO RENDIMENTO DO EXTRATO DA FOLHA DA ALOE ARBORESCENS
}

\author{
V.F. DA SILVA ${ }^{1}$, B. S. VALLE ${ }^{1}$, L.D. DA SILVA ${ }^{1}$, R. S. G. RIBEIRO ${ }^{1}$ e C. S.S. PEREIRA ${ }^{1}$ \\ ${ }^{1}$ Universidade de Vassouras, Faculdade de Engenharia Química \\ E-mail para contato: victoria_fred@hotmail.com
}

\begin{abstract}
RESUMO - Os produtos de origem natural apresentam uma infinidade de propriedades fitoterápicas e demonstram uma boa alternativa em substituição aos produtos sintéticos. A aloe arborescens é uma planta que possui diversas propriedades medicinais e cosméticas e é usada em todo mundo para tratar uma variedade de condições. Seu gel possui características hidratantes, nutritivas, umectantes, entre outras, sobressaindo-se no setor cosmético. Para obtenção do extrato empregou-se a técnica de extração por soxhlet, utilizando metanol e etanol como solventes. Ao analisar os rendimentos obteve-se um valor de 44,80 $\pm 1,34$ para metanol e 14,51 \pm 0,006 para etanol. Demonstrando assim, a eficiência máxima obtida em ternos quantitativos para metanol.
\end{abstract}

\section{INTRODUÇÃO}

Aloe arborescens, também conhecida como babosa, é uma planta de uso medicinal e cosmético, utilizada há mais de 2000 anos devido as suas propriedades fitoterápicas presente em sua composição. Suas folhas são suculentas e esverdeadas assemelhando-se a aparência de cactos. De acordo com Souza et al., 2016, existem cerca de 785 espécies, distribuídas em 18 gêneros distintos.

Embora a espécie apresente inúmeras outras propriedades medicinais, as cosméticas são as que mais chamam atenção devido aos agentes nutritivos, hidratantes, umectantes, adstringente, entre outras, contidos em seu gel, características as quais fazem com que esta planta possua uma ampla gama de aplicabilidade nos setores industriais. (Veggi, P. C., 2009).

Para obtenção do extrato do material vegetal, muitas técnicas podem ser empregadas como: maceração, prensagem, fluido pressurizado, soxhlet, entre outras (Alves et al.,2018). O interesse no processo de extração por solventes utilizando aparato soxhlet consiste na fácil manipulação e na confiabilidade de resultados. Nele é possível obter extratos mais concentrados e com menor chance de contaminação (Dhodare et al.,2015).

O objetivo deste trabalho foi avaliar o rendimento obtido através da extração das folhas de aloe arborescens utilizando metanol e etanol como solventes, bem como fazer uma análise comparativa através de experimento semelhante encontrado na literatura. 


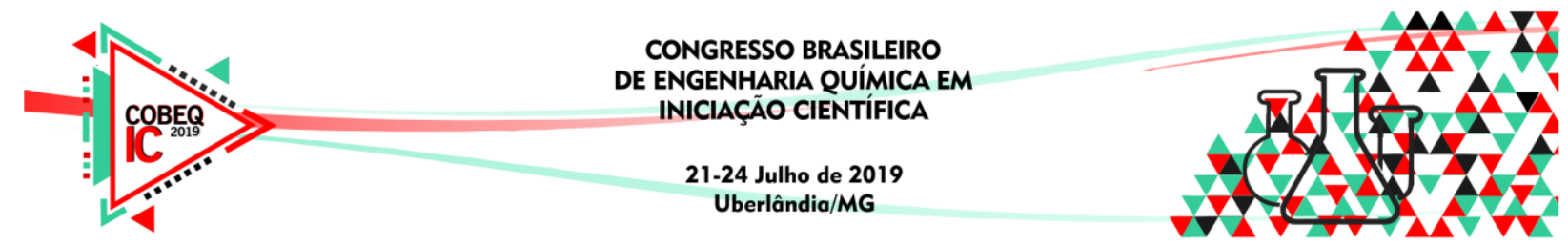

\section{MATERIAL E MÉTODO}

Os experimentos foram realizados no laboratório de Engenharia Química da Universidade de Vassouras. A aloe arborescens (babosa) utilizada foi coletada na cidade de Engenheiro Paulo de Frontin - RJ. A Figura 1 ilustra a matéria prima coletada.

Figura 1 - Aloe arborescens utilizada nos estudos de extração.

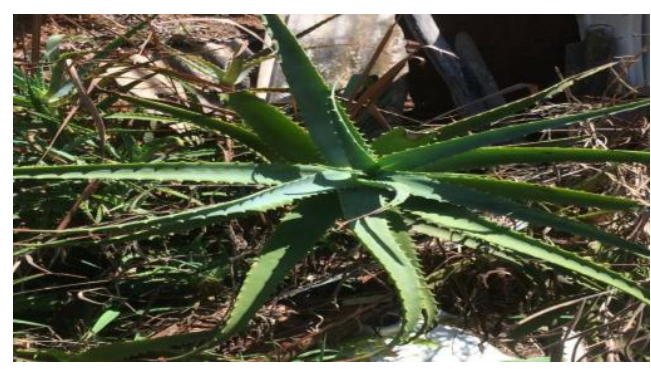

A extração foi realizada em triplicata em equipamento soxhlet. A folha bruta de babosa foi lavada para remoção de impurezas e cortada. Foram pesados cerca de $100 \mathrm{~g}$ da folha e transferidos para o cartucho. Foram utilizados $700 \mathrm{~mL}$ de cada solvente, sendo estes o metanol $(99,8 \%)$ e o etanol $(99,5 \%)$. Foi estabelecido um tempo de extração de 4 horas. A Figura 2 demonstra um aparato experimental de extração soxhlet.

Figura 2 - Esquema de montagem utilizando aparato Soxhlet.

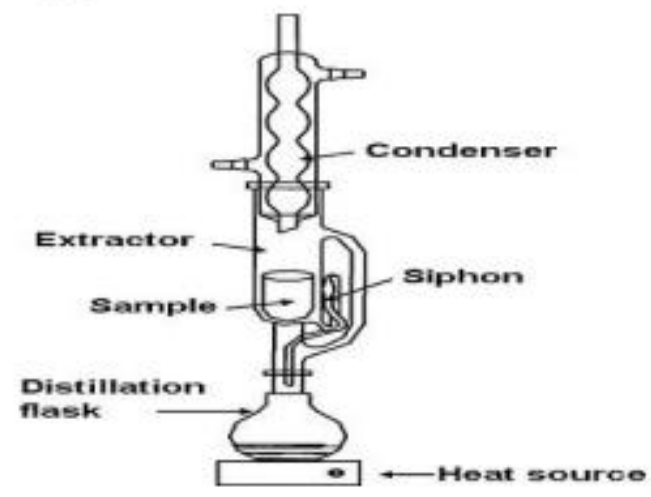

Após o processo de extração, o extrato passou por um processo de recuperação do solvente, utilizando um evaporador rotativo.

Os valores dos rendimentos foram obtidos aplicando a seguinte equação 1: 


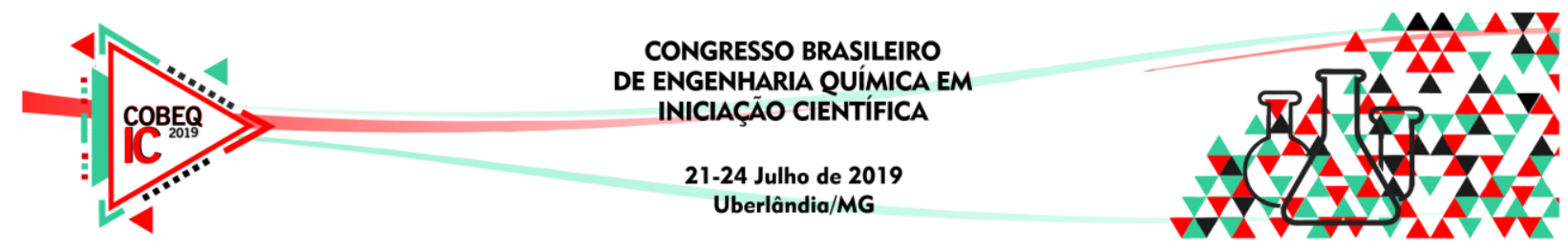

Rendimento do extrato $(\%)=\frac{m}{m} \times 10 \% x$

\section{RESULTADOS E DISCUSSÕES}

Os resultados das análises foram obtidos através de cálculos do rendimento do processo de extração realizado para os solventes metanol e etanol, conforme é mostrado nas Tabelas 1 e 2 .

Tabela 1 - Rendimento das amostras de extrato de aloe arborescens usando metanol

\begin{tabular}{|c|c|c|c|}
\hline Amostra & Massa inicial (g) & $\begin{array}{c}\text { Massa do extrato } \\
(\mathbf{g})\end{array}$ & Rendimento \% (g/g) \\
\hline \hline $\mathbf{1}$ & 100,027 & 44,413 & 44,40 \\
\hline $\mathbf{2}$ & 100,011 & 43,410 & 43,40 \\
\hline $\mathbf{3}$ & 100,055 & 46,630 & 46,60 \\
\hline
\end{tabular}

Tabela 2 - Rendimento das amostras de extrato de aloe arborescens usando etanol

\begin{tabular}{|c|c|c|c|}
\hline Amostra & Massa inicial (g) & $\begin{array}{c}\text { Massa do extrato } \\
(\mathbf{g})\end{array}$ & Rendimento \% (g/g) \\
\hline \hline $\mathbf{1}$ & 100,031 & 4,921 & 4,92 \\
\hline $\mathbf{2}$ & 100,022 & 4,794 & 4,79 \\
\hline $\mathbf{3}$ & 100,026 & 4,802 & 4,80 \\
\hline
\end{tabular}

Os valores obtidos pelos rendimentos dos processos extrativos foram de 44,80 $\pm 1,34$ para metanol e 14,51 $\pm 0,0058$ para etanol. Indicando maior eficiência para o solvente metanol.

Murakami et al, (2009), em seus experimentos, obteve um valor de rendimento de 22,93 (\%), utilizando 1.916, $95 \mathrm{~g}$ de matéria prima. O método extrativo empregado por ela foi de imersão em solvente etanol $(99,5 \%)$ trocados a cada 7 dias, trituração ao atingir o $21^{\circ}$ dia, retornando a imersão em etanol. Esta extração levou cerca de 28 dias até sua finalização.

Analisando os resultados obtidos no experimento, é possível concluir que o método por imersão gerou diferença de 8,42 (\%) a mais no rendimento do extrato comparado ao método extrativo utilizando soxhlet. Em contrapartida, a quantidade de matéria prima utilizada e o tempo gasto, não são interessantes para aplicação em escala industrial. Outra desvantagem da extração por imersão é a quantidade de solvente gasto, além da facilidade de contaminação do extrato, o que dificilmente poderá ocorrer na extração por soxhlet.

Não foram encontrados na literatura trabalhos que utilizaram metanol como solvente na extração das folhas da aloe arborescens. 


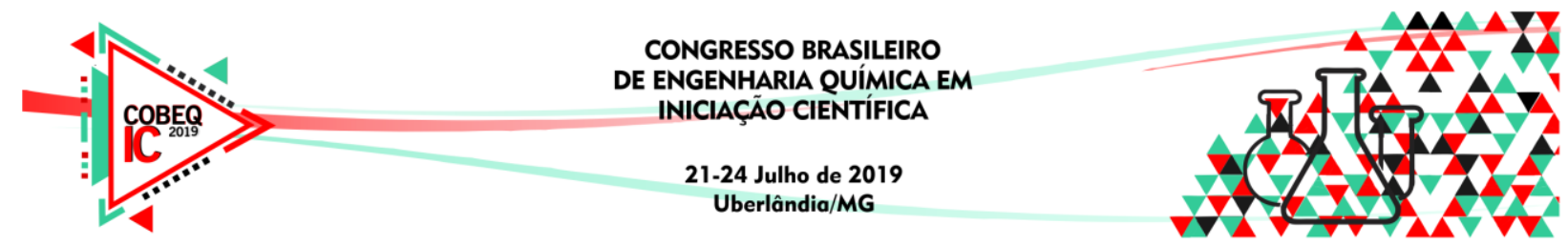

\section{CONCLUSÃO}

De modo geral, os rendimentos obtidos dos extratos da folha da aloe arborescens se mostraram satisfatórios para um processo de extração por solventes. Em comparação ao método extrativo encontrado na literatura, obtiveram-se valores próximos de rendimento e vantagens de extração por soxhlet, demonstrando possível aplicabilidade para este método. A Aloe vera é uma planta medicinal usada em todo mundo para tratar uma variedade de condições, embora a espécie apresente tais características comprovadas por estudos científicos, à autorização para utilização desta, vale apenas para produtos cosméticos e medicamentos de uso tópico com a função cicatrizante, de acordo com (Anvisa, 2016). Ainda assim, tem importante valor comercial.

\section{REFERÊNCIAS}

ALVES, M. M. A.; BARBOSA, A.; VIDAL, R. S. SANTOS, K. S. e DARIVA, C. Extração, caracterização e isolamento dos compostos do óleo essencial de nim empregando fluidos pressurizados. Semana de Pesquisa da Universidade Tiradentes SEMPESq, n. 18. Sergipe, 2018.

ANVISA. Informe técnico n. ${ }^{\circ}$ 47, de 16 de novembro de 2011.

DHODARE, G. D; WANDHARE, G. D; JIRAPURE, M. N; DUMORE, N. S. Extraction of Aloin from aloevera by using Soxhlet apparatus. International Journal for Engennering Applications and Technology, 2015.

FREITAS, V. S.; RODRIGUEES, R. A. F.; GASPI, F. O. G. Propriedades farmacológicas da Aloe vera (L) Burm. F. Rev. Bras. Pl. Med., Campinas, v.16, n.2, p.299-307, 2014

MURAKAMI, C.; CARDOSO, F. L. e MAYWOEM, M. A. S. Potencial fitotóxico de extratos foliares de Arborescens Miller (Asphodelaceae) produzidos em diferentes épocas do ano. Acta Botânica Brasilica. 23(1): 111-117. 2009.

VEGGI, P. C. Obtenção de extratos vegetais por diferentes métodos de extração: estudo experimental e simulação dos processos. 143 p. Dissertação (mestrado) - Universidade Estadual de Campinas, Faculdade de Engenharia de Alimentos, Campinas-SP, 2009. Disponível em: <http://www.repositorio.unicamp.br/handle/REPOSIP/254860>. Acesso em: 02 fev. 2019. 